The following is a pre-print of the original article:

Thomas Waechtler, Shao-Feng Ding, Lutz Hofmann, Robert Mothes, Qi Xie, Steffen Oswald, Christophe Detavernier, Stefan E. Schulz, Xin-Ping Qu, Heinrich Lang, and Thomas Gessner, "ALD-grown seed layers for electrochemical copper deposition integrated with different diffusion barrier systems", Microelectron. Eng. 88, 684-689 (2011).

ISSN: 0167-9317

Digital Object Identifier: 10.1016/j.mee.2010.07.004

Available via http://www.sciencedirect.com or http://dx.doi.org/10.1016/i.mee.2010.07.004 (C) 2010 Elsevier B.V. 


\title{
ALD-grown seed layers for electrochemical copper deposition integrated with different diffusion barrier systems
}

\author{
Thomas Waechtler ${ }^{1,2} *$, Shao-Feng Ding ${ }^{2,3}$, Lutz Hofmann ${ }^{2}$, Robert Mothes ${ }^{4}$, \\ Qi Xie $^{5}$, Steffen Oswald ${ }^{6}$, Christophe Detavernier ${ }^{5}$, Stefan E. Schulz ${ }^{1,2}$, Xin-Ping Qu ${ }^{3}$,
} Heinrich Lang ${ }^{4}$, and Thomas Gessner ${ }^{1,2}$

1 Fraunhofer Research Institution for Electronic Nano Systems (ENAS), Technologie-Campus 3, D-09126 Chemnitz, Germany

2 Center for Microtechnologies, Chemnitz University of Technology, D-09107 Chemnitz, Germany

3 State Key Laboratory of ASIC and System, Department of Microelectronics, Fudan University, Shanghai 200433, PR China

4 Institute of Chemistry, Department of Inorganic Chemistry, Chemnitz University of Technology, D-09107 Chemnitz, Germany

5 Department of Solid State Science, Ghent University, Krijgslaan 281/S1, B-9000 Ghent, Belgium

${ }^{6}$ Leibniz Institute for Solid-State and Materials Research (IFW), D-01069 Dresden, Germany

* Corresponding author;

Phone: +49 (0)371 / 45001-280,

Fax: +49 (0)371 / 45001-380,

E-Mail: thomas.waechtler@enas.fraunhofer.de

\begin{abstract}
The deposition of $\mathrm{Cu}$ seed layers for electrochemical $\mathrm{Cu}$ deposition (ECD) via atomic layer deposition (ALD) of copper oxide and subsequent thermal reduction at temperatures between 110 and $120^{\circ} \mathrm{C}$ was studied on different diffusion barrier systems. While optimization of the process is required on TaN with respect to reduction and plating, promising results were obtained on blanket PVD $\mathrm{Ru}$. The plating results on layers of ALD $\mathrm{Cu}$ with underlying $\mathrm{Ru}$ even outperformed the ones achieved on PVD Cu seed layers with respect to morphology and resistivity. Applying the processes to via and line patterns gave similar results, suggesting that a combination of ALD Cu with PVD or ALD-grown Ru could significantly improve the ECD Cu growth.
\end{abstract}

\section{Keywords}

Atomic layer deposition (ALD); Copper oxide; Reduction; Seed layer; Copper; Ruthenium; Electrochemical deposition (ECD); Interconnect 


\section{Introduction}

To fabricate interconnect systems via the Damascene approach in state-of-the-art ultra-largescale integrated (ULSI) devices, copper is deposited by electrochemical deposition (ECD) into patterned dielectrics coated before with a thin-film system comprising diffusion barriers and metallic nucleation layers. Physical vapor deposition (PVD) methods, commonly used to deposit barrier films and $\mathrm{Cu}$ seed layers, are facing difficulties with respect to film conformality and thickness homogeneity in the nanoscale interconnect features especially at larger wafer diameters. While pushing PVD ever closer to its limits to accommodate for the needs of the upcoming technology nodes [1], alternative film growth methods are highly desirable for $22 \mathrm{~nm}$ and beyond [2].

As a technique governed by self-limiting surface reactions, atomic layer deposition (ALD) offers unique possibilities for growing ultra-thin films conformally both across large substrates as well as in nanostructures. We therefore examine the deposition of $\mathrm{Cu}$ seed layers based on the ALD of copper oxide with an additional reduction step on different diffusion barrier systems and the application of these films as seed layers for subsequent Cu ECD.

\section{Experimental}

$\mathrm{Cu}_{2} \mathrm{O}$ films were deposited by thermal ALD from bis(tri- $n$-butylphosphane)copper(I)acetylacetonate $\left[\left({ }^{n} \mathrm{Bu}_{3} \mathrm{P}\right)_{2} \mathrm{Cu}(\mathrm{acac})\right](\mathrm{Bu}=$ butyl; acac $=$ acetylacetonate $)$ and wet $\mathrm{O}_{2}$ at $120^{\circ} \mathrm{C}$ [3]. A single-wafer vertical flow reactor capable of handling substrates up to $100 \mathrm{~mm}$ in diameter was used for the ALD processes. The $\mathrm{Cu}$ precursor was supplied using a Bronkhorst liquid delivery system. Water vapor was generated by a bubbler and mixed with $\mathrm{O}_{2}$ to generate wet oxygen as the oxidizing agent.

To reduce the copper oxide films to metallic copper after ALD, the samples were heat-treated in vapors of formic acid, based on earlier experience using this reducing agent during copper MOCVD [4] and considering the successful application of organic reducing agents for the reduction of copper oxide [5]. The reduction processes were carried out in-situ after ALD in the same chamber, whereby the formic acid vapor was generated by bubbling or liquid delivery. To avoid agglomeration of the films, the process temperature of $115^{\circ} \mathrm{C}$ was comparable to the ALD growth temperature.

To study the potential of the ALD films as seed layers for ECD, experiments were carried out using a $\mathrm{CuSO}_{4}$-based plating bath with a concentration of $25 \mathrm{~g} / \mathrm{L} \mathrm{Cu}$ and $180 \mathrm{~g} / \mathrm{L} \mathrm{H}_{2} \mathrm{SO}_{4}$ as well as a standard set of additives such as suppressor and grain refiner. This bath composition represents a standard formulation for metallization of printed circuit boards. The ECD experiments were conducted in a Walter Lemmen bench-type plating cell with parallel electrode configuration. Typically, the experiments were carried out in a "hot-entry" mode, meaning that the samples were introduced into the plating solution with a voltage applied in order to minimize etching of the $\mathrm{Cu}$ seed layer by the sulfuric acid contained in the bath. All processes were run under potentiostatic conditions.

The copper oxide / copper ALD and ECD processes were studied on different substrates. Blanket TaN films were obtained by reactive magnetron sputtering in a Balzers CLC 9000 equipment. Furthermore, blanket Si substrates coated with $100 \mathrm{~nm} \mathrm{Ru}$ on top of a $10 \mathrm{~nm} \mathrm{Ti}$ adhesion layer, both prepared by evaporation, were purchased from Advantiv Technologies, Inc. and used as received. For studies on interconnect patterns, thermal $\mathrm{SiO}_{2}$ films were 
patterned by electron-beam lithography and reactive ion etching (RIE) to give line and hole structures of different width ranging from $200 \mathrm{~nm}$ upwards. With an etching depth of $800 \mathrm{~nm}$ the highest aspect ratio in these patterns was 4, comparably to Dual Damascene interconnect structures [2]. These patterns were coated with TaN/Ru films both by sputtering and ALD. For the sputtered diffusion barrier / liner system, an Ulvac magnetron sputtering system was applied to deposit $10 \mathrm{~nm}$ thick TaN films with an additional Ru film between 5 and $15 \mathrm{~nm}$ thickness. In addition, ALD-grown stacks of $\sim 5 \mathrm{~nm}$ TaN with additional $\sim 4 \mathrm{~nm} \mathrm{Ru}$ on the $\mathrm{SiO}_{2}$ patterns were obtained by plasma-assisted ALD (PEALD) in a home-built reactor [6]. The TaN films were obtained at $200^{\circ} \mathrm{C}$ using pentakis(dimethylamino)tantalum(V) (PDMAT) and hydrogen as the precursors, while $\mathrm{Ru}$ was grown from bis(ethylcyclopentadienyl)ruthenium(II) $\left[\mathrm{Ru}\left(\eta^{5}-\mathrm{C}_{5} \mathrm{H}_{4} \mathrm{Et}\right)_{2}\right]\left(\mathrm{Et}=\right.$ ethyl) with $\mathrm{NH}_{3}$ as the coreactant.

The copper oxide ALD samples were characterized by spectroscopic ellipsometry for the thickness of the ALD films using a SENTECH SE850 ellipsometer. X-ray photoelectron spectroscopy with $\mathrm{Al} \mathrm{K \alpha}$ X-rays (1486.7 eV, monochromatic) for excitation on Physical Electronics PHI Quantum 2000 and PHI 5600 equipments was applied to study the chemical state of the copper and copper oxides. Scanning electron microscopy (SEM) using a LEO DSM 982 and a ZEISS Supra 60 were applied for morphological characterization of the samples. The surface roughness was determined by atomic force microscopy (AFM) using a Digital Instruments NanoScope IIIa Dimension 3000 with standard silicon tips in tapping mode. Sheet resistance was measured by the four-point probe method with an Omnimap RS 35 equipment.

\section{Results and Discussion}

Using the combination of $\left[\left({ }^{n} \mathrm{Bu}_{3} \mathrm{P}\right)_{2} \mathrm{Cu}(\mathrm{acac})\right]$ and wet oxygen, thermal ALD of copper oxide was shown earlier on a number of substrates, including $\mathrm{SiO}_{2}, \mathrm{TaN}$, and $\mathrm{Ru}$ at temperatures between 100 and $135^{\circ} \mathrm{C}$ [3]. Linear, two-dimensional growth was obtained on TaN, while island growth with later coalescence towards continuous films occurred on $\mathrm{SiO}_{2}$ [7]. On both substrates, well-saturated film growth regimes were found as revealed by the characteristics shown in Fig. 1, confirming the typical ALD growth behavior. While on TaN the ALD films were well separated from the diffusion barrier, complete growth saturation was not achieved on $\mathrm{Ru}$. First investigations suggest that strong intermixing occurring on evaporated $100 \mathrm{~nm}$ thick Ru films could have contributed to this effect [8]. However, further investigations are underway for a detailed study of the copper oxide growth process on the different substrates.

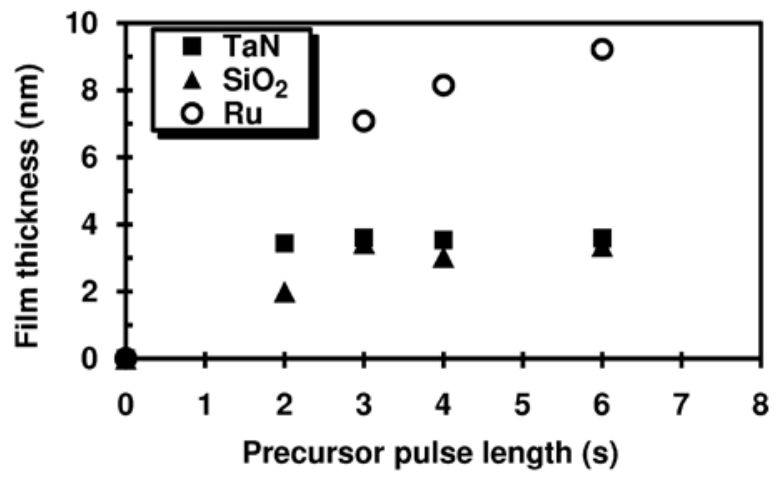

Fig. 1. Growth saturation during copper oxide ALD on $\mathrm{TaN}, \mathrm{SiO}_{2}$, and $\mathrm{Ru}$ at $120^{\circ} \mathrm{C}$. 


\subsection{Reduction Processes}

Post-treating the copper oxide films in vapor phase processes using formic acid showed effective reduction especially on Ru. Fig. 2 displays $\mathrm{Cu} 2 \mathrm{p}$ and $\mathrm{Cu}$ LMM spectra of copper oxide films on blanket $100 \mathrm{~nm}$ Ru directly after ALD and after subsequent formic acid treatment. It can clearly be seen from the $\mathrm{Cu} 2 \mathrm{p} 3 / 2$ data between 930 and $945 \mathrm{eV}[9,10]$ as well as from the change in the $\mathrm{Cu} 2 \mathrm{p} 1 / 2$ peak at 952 to $954 \mathrm{eV}$ [11] that $\mathrm{Cu}(\mathrm{II})$ contributions present after ALD are largely removed during the reduction process. Furthermore, the $\mathrm{Cu}$ LMM spectrum reveals the formation of metallic copper [9, 10, 12]. Nevertheless, some $\mathrm{Cu}(\mathrm{I})$ oxide is still present after the formic acid process. This may either be due to incomplete reduction or is caused by a certain degree of re-oxidation because the sample was in contact to air for about one day before the XPS analysis.

The effectiveness of the process is also revealed by sheet resistance measurements: While the $R_{S}$ values of the as-deposited Ru wafers typically are in the range of 9 to $10 \Omega / \square$, the samples showed a decrease in sheet resistance between 26 and $42 \%$ after 600 ALD cycles at $120^{\circ} \mathrm{C}$ and an additional formic acid treatment at $115^{\circ} \mathrm{C} / 20 \mathrm{~min}$. Resistivity reduction of the $\mathrm{Ru}$ layer, which could be due to annealing effects and hence overlay the results, were ruled out by control experiments. Annealing similar Ru samples at comparable conditions in the ALD reactor for similar durations as the ALD processes did not exhibit a significant reduction in sheet resistance. Therefore, the decrease in $\mathrm{R}_{\mathrm{S}}$ can be attributed to the formation of metallic copper as result of the ALD and the reduction process.

In contrast to $\mathrm{Ru}$, the results obtained for ALD films on TaN were not as distinct. Reducing activity of formic acid treatments on aged samples with ALD-grown copper oxide films is indicated by XPS as displayed in Fig. 3. However, complete removal of copper(I) or copper(II) oxides and formation of $\mathrm{Cu}(0)$ could not be shown when using fresh ALD samples (Fig. 4). The XPS spectra shown in Fig. 4 reveal that also after the reduction process strong $\mathrm{Cu}(\mathrm{II})$ signals are present, although the peaks which can be assigned to $\mathrm{Cu}(\mathrm{I})$ and $\mathrm{Cu}(0)$ also increase. Most likely, some of the $\mathrm{Cu}(\mathrm{II})$ was reduced to $\mathrm{Cu}(\mathrm{I})$ as obtained for aged films. From the $\mathrm{Cu} \mathrm{LMM}$ spectrum a slight shoulder indicating the formation of $\mathrm{Cu}(0)$ can also be seen, while the main peak is shifted to higher binding energy, which is not explainable with any copper compounds. A possible formation of metallic, hence conductive, copper is also supported by a minor, but measurable decrease in the sheet resistance after the reduction process. From the respective film thickness, the specific resistivity was calculated. Plotting the data together with resistivity values reported by Liu et al. [13] for evaporated copper on silica as depicted in Fig. 5 reveals that although the resistivity of the ALD films is between 500 and $1800 \mu \Omega \mathrm{cm}$, the values appear reasonable when compared to the evaporated films, given their low thickness. On the other hand, one also has to take into account that the films were not completely reduced, or at least re-oxidized due to air exposure. 

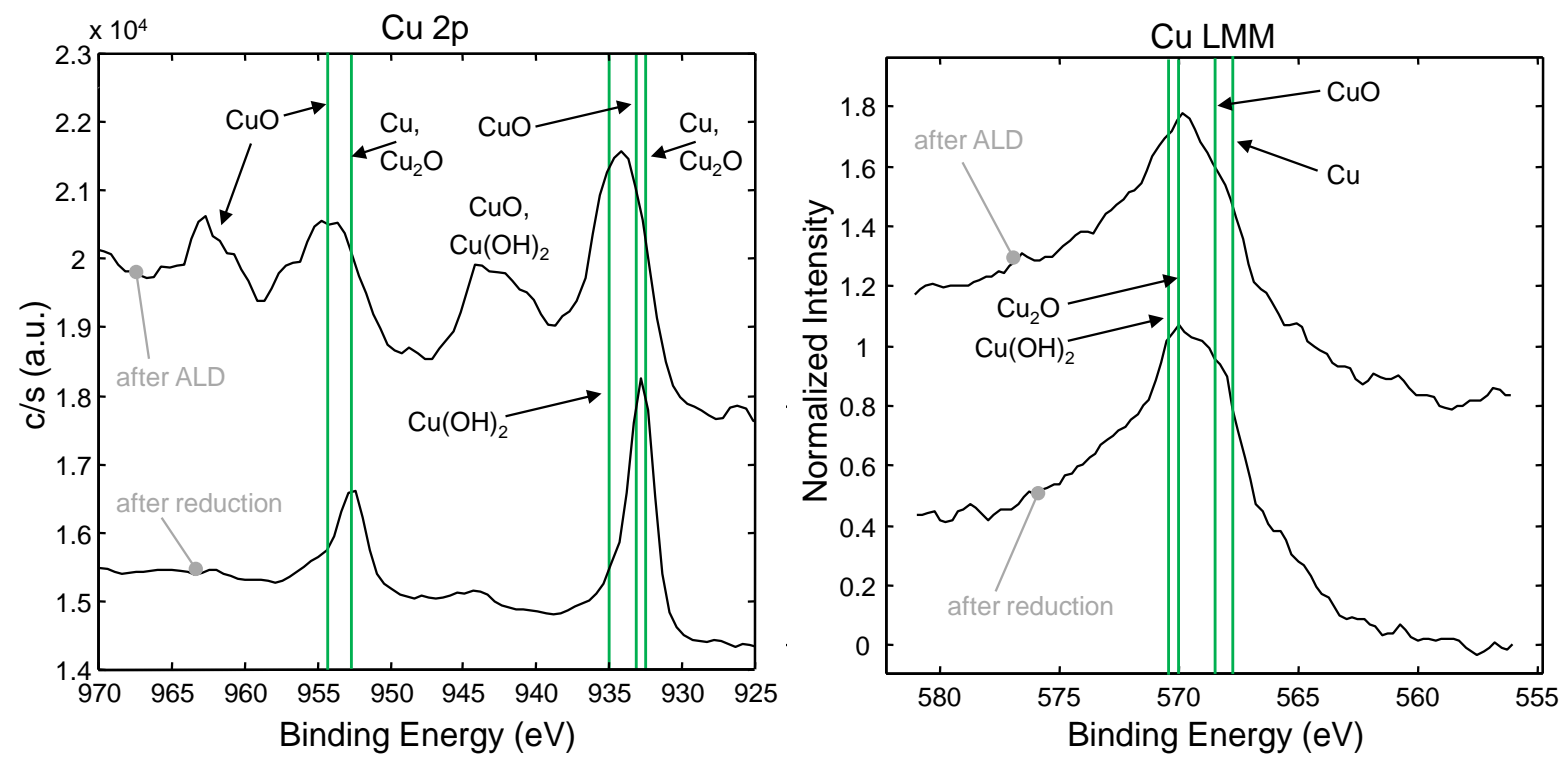

Fig. 2. $\mathrm{Cu} 2 \mathrm{p}$ and $\mathrm{Cu}$ LMM spectra of copper oxide films grown on Ru after ALD as well as after subsequent formic acid treatment.

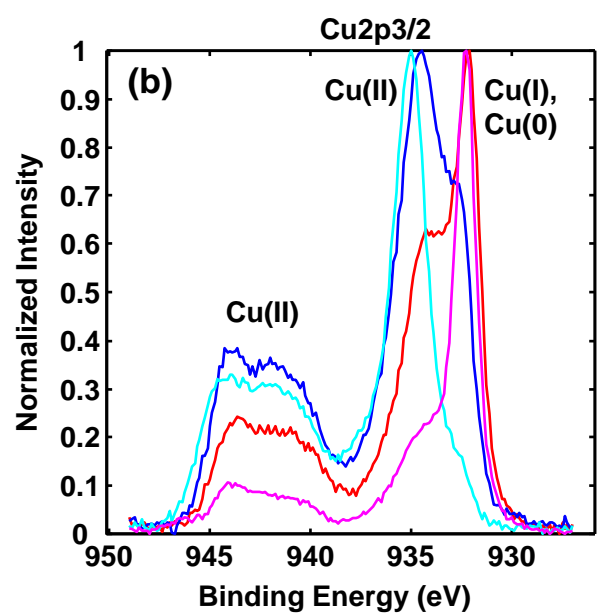

ALD on TaN +6 weeks in air

ALD on TaN +72 weeks in air

Reduction formic acid $115 \mathrm{C}+6$ weeks in air

Reduction formic acid $115 \mathrm{C}+25$ weeks in air
Fig. 3. XPS analysis of $\mathrm{ALD} \mathrm{Cu}_{2} \mathrm{O}$ grown on TaN after storage in air before and after reduction with formic acid vapor. It is seen that slowly the $\mathrm{Cu}(\mathrm{I})$ state present after the ALD changes to $\mathrm{Cu}(\mathrm{II})$ upon exposure to air, while it is restored upon reduction, to give $\mathrm{Cu}(\mathrm{I})$ and potentially $\mathrm{Cu}(0)$. 

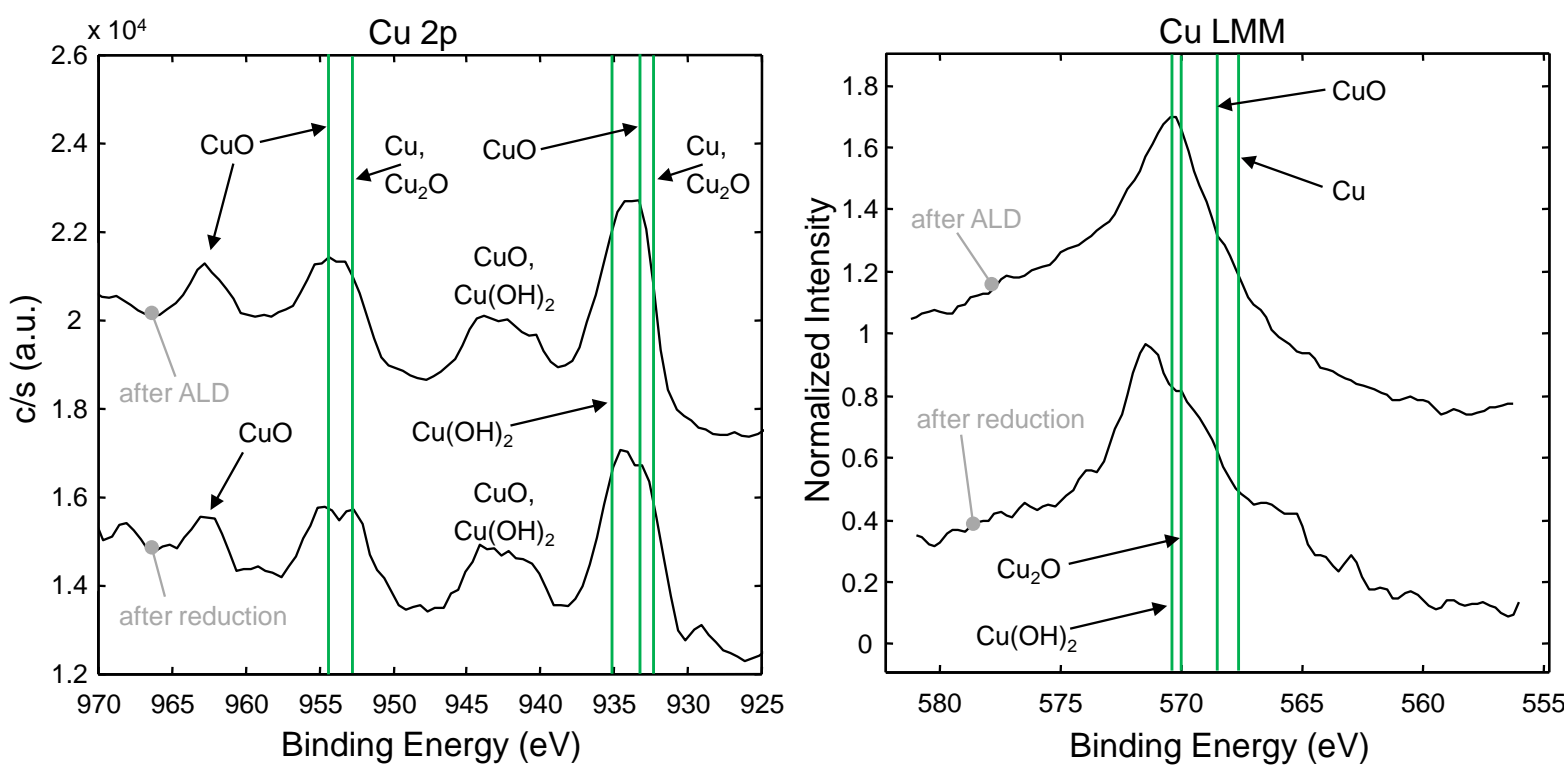

Fig. 4. $\mathrm{Cu} 2 \mathrm{p}$ and $\mathrm{Cu}$ LMM spectra of copper oxide films grown on TaN after ALD as well as after subsequent formic acid treatment.

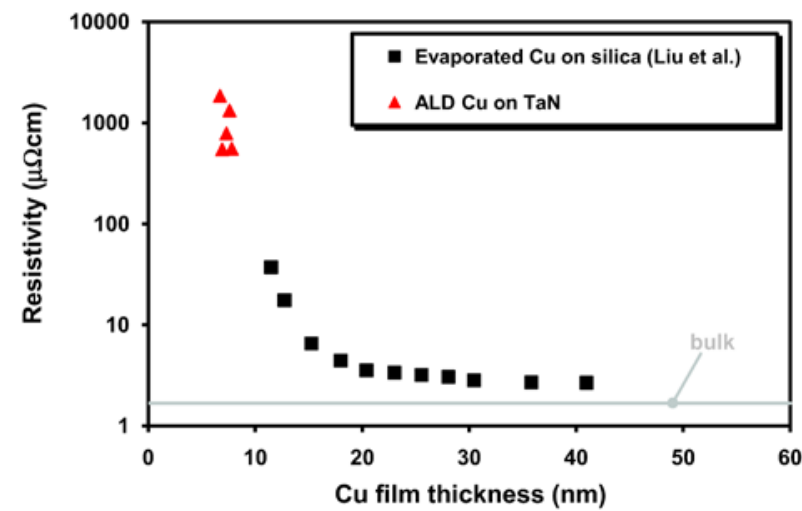

Fig. 5. Resistivity of ALD Cu films on TaN after formic acid reduction compared to data reported by Liu et al. [13] for evaporated $\mathrm{Cu}$ films on silica. The bulk value of the specific resistivity of copper $(1.7 \mu \Omega \mathrm{cm})$ is given as a gray line.

To analyze these results, the issue why the formic acid treatment appears substantially more effective on $\mathrm{Ru}$ than on TaN substrates needs to be discussed. As mentioned above, the films on $\mathrm{Ru}$ and TaN were prepared in similar ALD processes, leading to a copper oxide thickness on TaN of $\sim 5 \mathrm{~nm}$, while an ellipsometric thickness of $\sim 12 \mathrm{~nm}$ was obtained on $\mathrm{Ru}$. Therefore, even if complete reduction during the formic acid treatment occured, re-oxidation due to air exposure before the XPS analysis would have had a much more detrimental effect to the thinner films on TaN. However, more likely, these differences may result from the behavior formic acid exhibits on different metallic surfaces. It is well known that on many transition metals formic acid undergoes catalytic dissociation towards hydrogen [14, 15]. While no such activity is reported for TaN, $\mathrm{Cu}$ is somewhat active [15]. For $\mathrm{Ru}$, in contrast, strong activity has been reported with respect to formic acid decomposition. Depending on the crystal orientation, two possible decomposition pathways, dehydration and dehydrogenation are known, both giving reducing species [15]. On $\mathrm{Cu}$ surfaces, in contrast, only dehydrogenation has been observed. From this point of view, it therefore appears most likely that the $\mathrm{Ru}$ underlayers promote the reduction of the copper oxide films during formic acid treatment. 


\subsection{Electrochemical Copper Deposition on ALD Seed Layers}

\section{TaN Diffusion Barriers}

For experiments with TaN diffusion barriers, a $\mathrm{Cu}$ seed layer of 5 to $6 \mathrm{~nm}$ thickness was obtained by ALD and in-situ reduction with formic acid as described above. After the process, the wafers were immediately transferred to the ECD processes to avoid extensive air exposure of the seed layers. However, the results of these experiments were not satisfactory. Independently of the plating conditions, only rough, coarse-grained copper was obtained from the electroplating. Fig. 6 a shows a top-view SEM image of a typical sample. In comparison, Fig. $6 \mathrm{~b}$ displays the plating result obtained on a $\sim 11 \mathrm{~nm}$ thick Cu seed layer with $30 \mathrm{~nm}$ TiN diffusion barrier, prepared by sputtering without vacuum break. The continuous $\mathrm{Cu}$ film obtained by ECD is in strong contrast to the grainy structure on the ALD-seeded TaN. Nevertheless, to evaluate these results, the resistivity of the seed layers has to be compared. For the sputtered $\mathrm{Cu}$ film a specific resistivity of $17 \mu \Omega \mathrm{cm}$ was calculated from four-point probe measurements, which is comparable to the values reported by Liu et al. [13] for evaporated $\mathrm{Cu}$ films of similar thickness (Fig. 5). Therefore, the film growth during ECD can be expected to proceed much more controlled on the PVD seed layer than on the ALD-seeded substrates, having 10 to 100 times higher resistivity of the copper film. Another influence is likely to stem from the overall way the barrier/seed layer stack was prepared. While the ALD films were deposited on TaN layers that had been exposed to air before, the $\mathrm{Cu} / \mathrm{TiN}$ stacks were sputtered without vacuum break, ruling out any barrier oxidation and hence ensuring a better defined interface between the copper film and the diffusion barrier, also with respect to subsequent ECD. Another influence towards the plating results on the ALD seed layers could stem from an incomplete reduction or potential re-oxidation of the ALD films due to air exposure, as discussed above. Since copper oxide is removed by the $\mathrm{H}_{2} \mathrm{SO}_{4}$ solution even under hot-entry conditions, this could have led to defective seed layers, so that during ECD the copper film would have to be grown directly on the TaN barrier. Indeed, plating experiments on air-exposed $\mathrm{TaN}$ without any $\mathrm{Cu}$ seed layers gave very similar results as shown in Fig. 6 a, strongly supporting this hypothesis. Nevertheless, it must be noted that a quasi standard chemistry of the plating bath was used. For a similar electrolyte solution almost the same behavior regarding grainy $\mathrm{Cu}$ growth on TiN was reported by Kim and Duquette [16]. However, after optimizing the bath composition mainly with respect to $\mathrm{pH}$, the authors report that much smoother films were obtained on TiN without seed layer. Considering this, it appears likely that for process integration optimizing both the ALD and the ECD process towards each other could lead to improved results. 

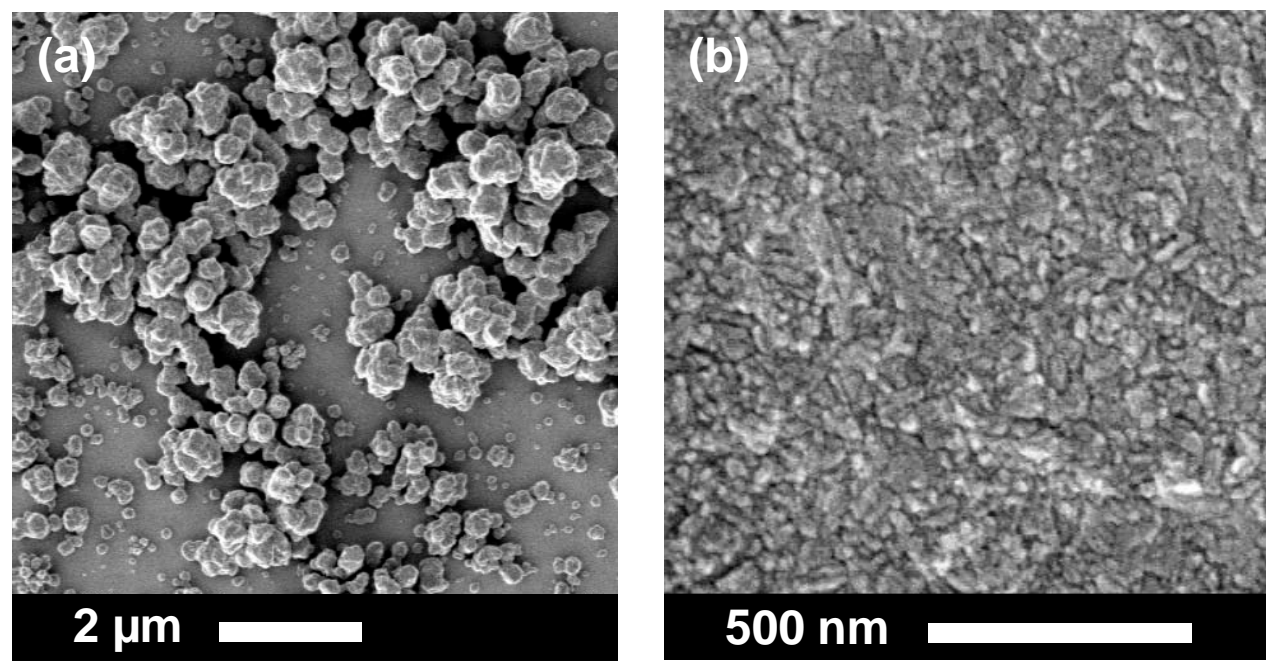

Fig. 6. Top-view SEM images of ECD Cu obtained on $40 \mathrm{~nm}$ air-exposed PVD TaN with $\sim 6 \mathrm{~nm}$ ALD Cu seed layer (a), and (b) on $30 \mathrm{~nm}$ PVD TiN with an in-situ sputtered Cu seed layer of $11 \mathrm{~nm}$ thickness. For the experiments, quarters of $100 \mathrm{~mm}$ wafers were used and a current of $80 \mathrm{~mA}$ was applied for $9 \mathrm{~min}$ in case of sample (a) while $60 \mathrm{~mA}$ were flown for 5 min in case of sample (b).

\section{Ru Underlayers}

For comparison, ECD studies were carried out on blanket $100 \mathrm{~nm}$ thick evaporated Ru films with and without ALD-grown $\mathrm{Cu}$. Furthermore, plating experiments were conducted on similar samples with sputtered $\mathrm{Cu}$ seed layers of equal thickness as the ALD films. Quarters of $100 \mathrm{~mm}$ wafers were used for these experiments. The plating conditions are given in Table 1. For the samples shown here, a constant voltage of $0.4 \mathrm{~V}$ was applied, leading to a plating current depending on the resistivity of the respective wafer. Fig. 7 shows top-view SEM images of ECD Cu films deposited on Ru (a), on Ru with PVD Cu seed layer (b), and on $\mathrm{Ru}$ seeded with ALD Cu (c). Table 2 summarizes the properties of the ECD Cu films obtained. Plating on Ru directly during a processing time of $300 \mathrm{~s}$ led to rough, coarse films as shown in Fig. 7 a. From four-point probe sheet resistance measurements, a comparably high resistivity of $3.2 \mu \Omega \mathrm{cm}$ was calculated. In comparison, the ECD processes repeatedly proceeded in a very controlled manner with an ALD $\mathrm{Cu}$ seed layer on $\mathrm{Ru}$. For example, during a plating time of only $120 \mathrm{~s}$, a Cu film of $285 \mathrm{~nm}$ thickness was obtained at a current of $200 \mathrm{~mA}$ (Fig. 7 c). Compared to the film grown on Ru directly, a resistivity of only $2.8 \mu \Omega \mathrm{cm}$ was measured for a slightly lower film thickness. Also with respect to morphology and roughness, the $\mathrm{Cu}$ obtained on ALD-seeded $\mathrm{Ru}$ appeared superior to the ECD films deposited on Ru without an ALD seed layer. They even surpassed the ones obtained on the sputtered $\mathrm{Cu}$ seed layers, as shown by the AFM images in Fig. 8. Nevertheless, given the lower thickness of the ECD Cu grown on the PVD seed layer and the thickness dependence of the resistivity, a direct comparison of the values calculated for the films on ALD and PVD Cu would be misleading. 
Table 1. Conditions of the Cu electroplating processes for the samples shown in Fig. 7 and Fig. 8.

\begin{tabular}{|l|l|l|l|}
\hline Substrate & Voltage (V) & Current (mA) & Time (s) \\
\hline $\mathrm{Ru}$ & 0.4 & 150 & 300 \\
\hline $\mathrm{Ru}+\mathrm{PVD} \mathrm{Cu}$ & 0.4 & 120 & 120 \\
\hline $\mathrm{Ru}+\mathrm{ALD} \mathrm{Cu}$ & 0.4 & 200 & 120 \\
\hline
\end{tabular}

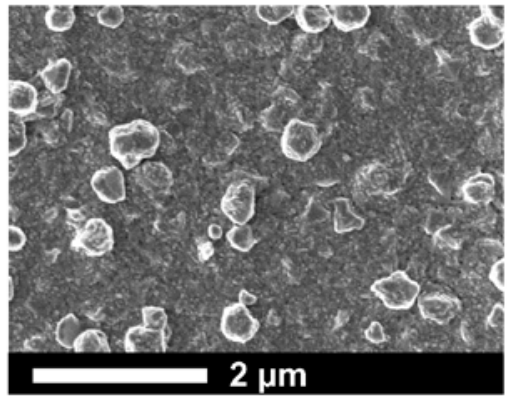

(a)

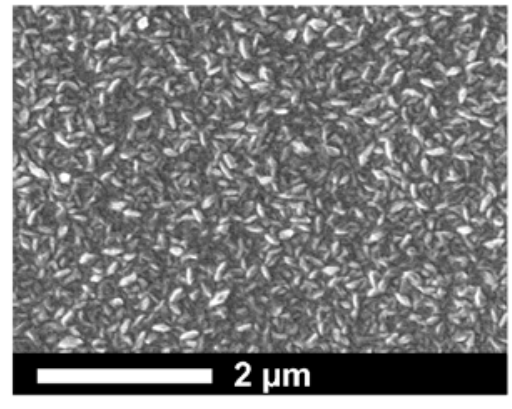

(b)

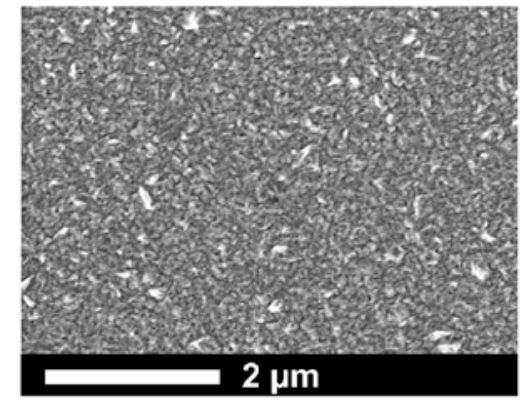

(c)

Fig. 7. Top-view SEM images of ECD Cu films obtained on plain Ru (a), on Ru with a $9 \mathrm{~nm}$ sputtered Cu seed layer (b), and on Ru with a $8 \mathrm{~nm}$ ALD-grown Cu seed layer (c).
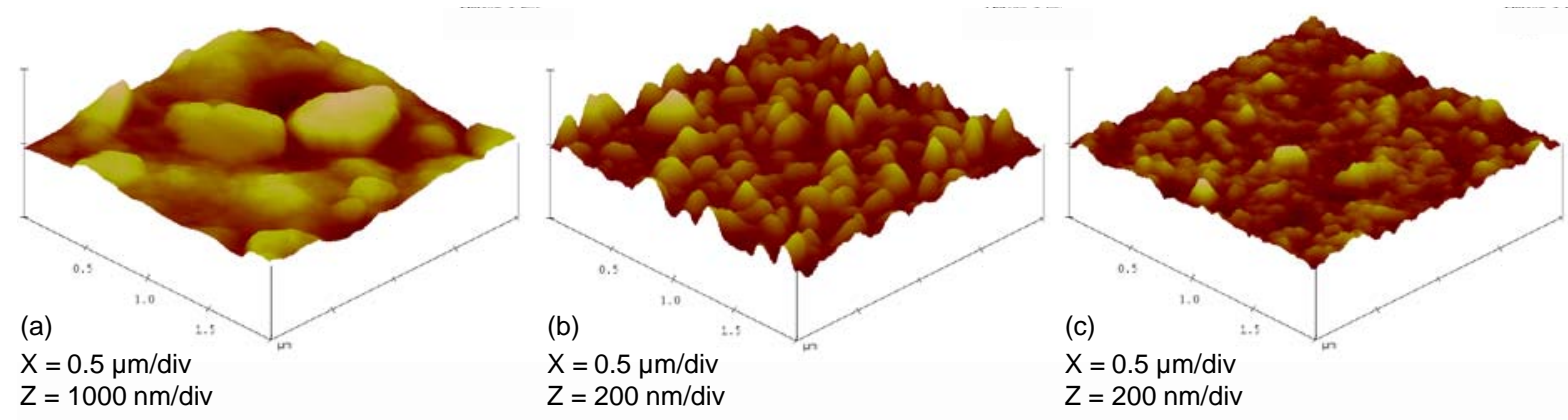

Fig. 8. AFM images of ECD Cu films obtained on plain $\mathrm{Ru}(\mathrm{a})$, on $\mathrm{Ru}$ with a $9 \mathrm{~nm}$ sputtered Cu seed layer (b), and on Ru with a 8 nm ALD-grown Cu seed layer (c).

Table 2. Thickness, specific resistivity $\rho$, and RMS roughness of ECD-grown $\mathrm{Cu}$ films on $\mathrm{Ru}$ directly as well as on Ru with a $9 \mathrm{~nm}$ sputtered and a $\sim 8 \mathrm{~nm}$ ALD-grown Cu seed layer. The plating conditions are summarized in Table 1.

\begin{tabular}{|l|l|l|l|}
\hline Substrate & ECD Cu thickness $(\mathbf{n m})$ & $\boldsymbol{\rho}(\boldsymbol{\mu} \mathbf{\Omega c m})$ & RMS roughness $(\mathbf{n m})$ \\
\hline $\mathrm{Ru}$ & 320 & 3.2 & 86.0 \\
\hline $\mathrm{Ru}+\mathrm{PVD} \mathrm{Cu}$ & 118 & 3.4 & 18.9 \\
\hline $\mathrm{Ru}+\mathrm{ALD} \mathrm{Cu}$ & 285 & 2.8 & 10.4 \\
\hline
\end{tabular}

Based on these findings, the investigations were extended to patterned $\mathrm{SiO}_{2}$ substrates of aspect ratio up to 4 comparable to Dual Damascene structures, having sputtered and ALDgrown TaN/Ru barrier film systems. Similarly to the blanket $\mathrm{Ru}$ films, $\mathrm{Cu}_{2} \mathrm{O}$ was grown during $600 \mathrm{ALD}$ cycles at $120^{\circ} \mathrm{C}$. An in-situ reduction step using formic acid vapor at $115^{\circ} \mathrm{C} /$ 
20 min was applied to convert the ALD film to metallic Cu. Subsequently, Cu ECD was conducted on these samples. For comparison, ECD was also conducted on patterned samples having the sputtered or ALD-grown $\mathrm{Ru} / \mathrm{TaN}$ film system but no additional ALD $\mathrm{Cu}$. The conditions of the electroplating processes are summarized in Table 3. The experiments were carried out on square wafer pieces of $\sim 3 \times 3 \mathrm{~cm}^{2}$, applying a constant voltage of $0.4 \mathrm{~V}$ as for the blanket films. Results of these experiments with sputtered $\mathrm{Ru} / \mathrm{TaN}$ barriers are shown in Fig. 9. Cross-sectional SEM micrographs after Cu electroplating in $\sim 370 \mathrm{~nm}$ wide and $\sim 850$ nm deep lines are shown. As Fig. 9 a displays, porous and grainy $\mathrm{Cu}$ deposits are obtained on $\mathrm{Ru}(10 \mathrm{~nm}) / \mathrm{TaN}(10 \mathrm{~nm})$ without ALD Cu. In contrast, much denser Cu films along with an improved filling behavior result on $\mathrm{Ru} / \mathrm{TaN}$ seeded with ALD Cu (Fig. $9 \mathrm{~b}$ ). First results obtained on ALD-grown Ru (4 nm) / TaN (5 nm) diffusion barrier systems with and without similar ALD $\mathrm{Cu}$ seed layers also suggest that the ECD copper growth proceeds more controlled when an ALD copper seed layer is used in addition to the $\mathrm{Ru}$. However, more detailed investigations are currently underway and will be communicated in due course.

Table 3. Conditions of the $\mathrm{Cu}$ electroplating processes for the patterned samples with PVD $\mathrm{Ru} / \mathrm{TaN}$ underlayers shown in Fig. 9.

\begin{tabular}{|l|l|l|l|}
\hline Substrate & Voltage (V) & Current (mA) & Time (s) \\
\hline PVD Ru $(10 \mathrm{~nm}) / \mathrm{TaN}(10 \mathrm{~nm})$ & 0.4 & 180 & 120 \\
\hline $\begin{array}{l}\text { PVD Ru }(10 \mathrm{~nm}) / \mathrm{TaN}(10 \mathrm{~nm}) \\
+ \text { ALD Cu }\end{array}$ & 0.4 & 250 & 120 \\
\hline
\end{tabular}
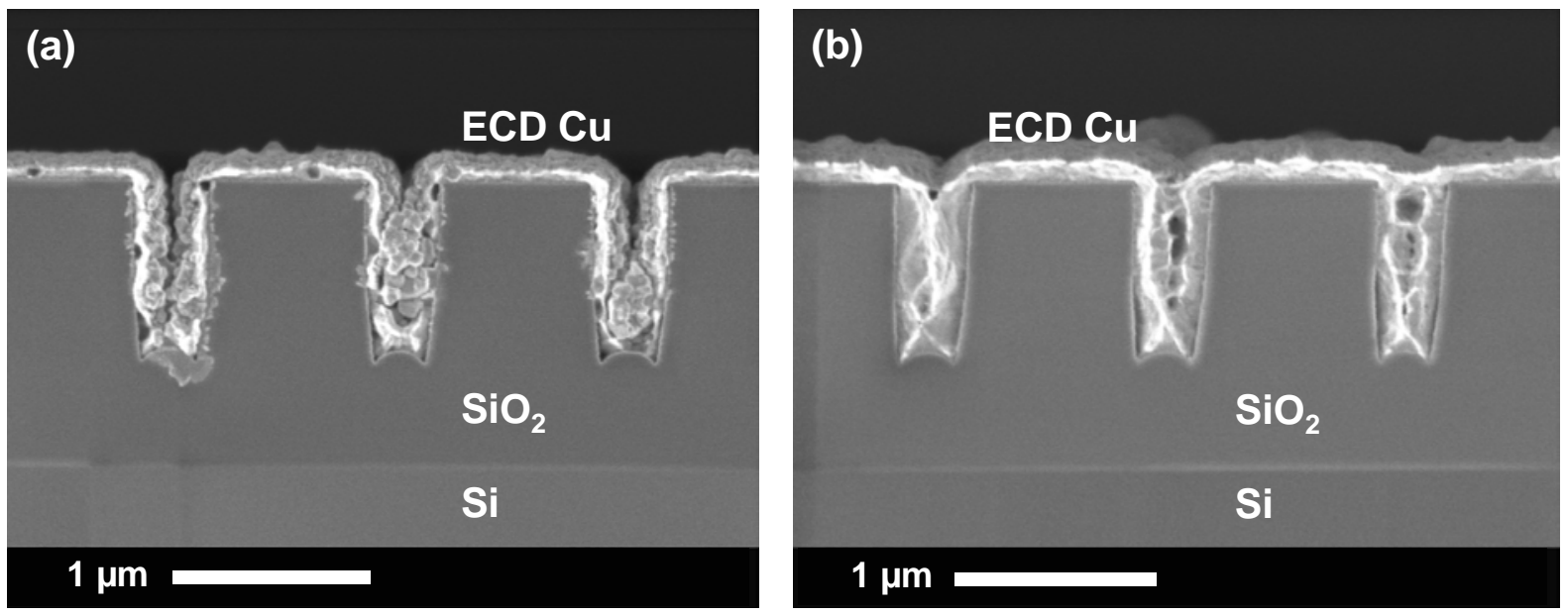

Fig. 9. Cross-sectional SEM images of ECD Cu films on $\mathrm{SiO}_{2}$ patterns having a sputtered $10 \mathrm{~nm} \mathrm{Ru} / 10 \mathrm{~nm}$ TaN film stack (a) without and (b) with an additional ALD Cu seed layer of $\sim 8 \mathrm{~nm}$ nominal thickness.

\section{Summary and Conclusions}

A processing sequence to deposit ultra-thin copper films by atomic layer deposition of copper oxide from a $\mathrm{Cu}(\mathrm{I}) \beta$-diketonate precursor and wet oxygen and additional reduction with formic acid at temperatures between 110 and $120^{\circ} \mathrm{C}$ has been reported. The copper films obtained on TaN as well as $\mathrm{Ru} / \mathrm{TaN}$ diffusion barrier systems were applied as seed layers for electrochemical copper deposition. While grainy ECD $\mathrm{Cu}$ growth resulted on TaN, the results 
suggest that the combination of $\mathrm{Ru}$ with a $\mathrm{Cu}$ seed layer can improve the ECD growth and filling behavior, and lead to a considerably higher film quality in similar plating processes. In this respect, ALD-grown Cu seed layers appear even more advantageous compared to PVD $\mathrm{Cu}$. These results are in line with a recent study by $\mathrm{Wu}$ and Eisenbraun [17]. The authors report that PEALD-grown $\mathrm{Cu}$ seed layers integrated with a PEALD $\mathrm{Ru}$ liner on a TaN diffusion barrier gave considerably better ECD results with respect to film roughness and void-free filling of interconnect features compared to samples without $\mathrm{Ru}$. Ru may therefore be regarded an enabler for the extension of copper metallization to future generations of ULSI devices, particularly when PVD-based techniques fail, so that ALD processes have to be introduced. In this case, especially the currently used Ta film serving as an adhesion layer between the TaN barrier and $\mathrm{Cu}$ seed layer could be replaced by $\mathrm{Ru}$, as Ta deposition by ALD appears to be rather cumbersome [18]. On the other hand, it has also been shown that Ru alone does not serve as a reliable $\mathrm{Cu}$ diffusion barrier [19], so that transition-metal nitride films will most likely continue to be required. In this respect, Ru-containing nitrides such as Ru-TaN, Ru-TiN, or Ru-WCN have been proposed [20-24]. At the same time, such mixedphase barriers could also help circumvent the issues observed during ECD on TaN seeded with ALD Cu. Therefore, future work will comprise optimizing both the ALD and ECD processes on barriers containing $\mathrm{Ru}$, also with respect to filling of demanding interconnect features.

\section{Acknowledgments}

We thank the German Research Foundation (DFG) for funding this work within the International Research Training Group IRTG 1215 "Materials and Concepts for Advanced Interconnects". Financial support obtained from the Fonds der Chemischen Industrie is also gratefully acknowledged. Jochen Albrecht and Dr. André Möller (SGS Institut Fresenius Dresden) are acknowledged for helpful discussions.

\section{References}

J. Forster, Advanced Metallization Conference 2009 (AMC 2009), Baltimore, MD (USA), 13-15 October 2009

ITRS - The International Technology Roadmap for Semiconductors, available at http://www.itrs.net/

T. Waechtler, S. Oswald, N. Roth, A. Jakob, H. Lang, R. Ecke, S.E. Schulz, T. Gessner, A. Moskvinova, S. Schulze, M. Hietschold, Journal of The Electrochemical Society 156 (2009) H453-H459.

J.A.T. Norman, M. Perez, S.E. Schulz, T. Waechtler, Microelectronic Engineering 85 (2008) 2159-2163.

P.J. Soininen, K.-E. Elers, V. Saanila, S. Kaipio, T. Sajavaara, S. Haukka, Journal of The Electrochemical Society 152 (2005) G122-G125.

Q. Xie, Y.-L. Jiang, C. Detavernier, D. Deduytsche, R.L. van Meirhaeghe, G.-P. Ru, B.-Z. Li, X.-P. Qu, Journal of Applied Physics 102 (2007) 083521.

T. Waechtler, N. Roth, R. Mothes, S. Schulze, S.E. Schulz, T. Gessner, H. Lang, M. Hietschold, ECS Transactions 25 (2009) 277-287. 
[8] T. Waechtler, S. Schulze, L. Hofmann, S. Hermann, N. Roth, S.E. Schulz, T. Gessner, H. Lang, M. Hietschold, Poster Presentation, AVS Atomic Layer Deposition Conference 2009 (ALD 2009), Monterey, CA (USA), 19-22 July 2009, available at http://archiv.tuchemnitz.de/pub/2009/0129/index.html

[9] J. Ghijsen, L.H. Tjeng, J. van Elp, H. Eskes, J. Westering, G.A. Sawatzky, M.T. Czyzyk, Physical Review B 38 (1988) 11322-11330.

[10] N.S. McIntyre, S. Sunder, D.W. Shoesmith, F.W. Stanchell, Journal of Vacuum Science and Technology 18 (1981) 714-721.

[11] J.G. Jolley, G.G. Geesey, M.R. Haukins, R.B. Write, P.L. Wichlaz, Applied Surface Science 37 (1989) 469-480.

[12] S.W. Gaarenstroom, N. Winograd, Journal of Chemical Physics 67 (1977) 3500-3506.

[13] H.-D. Liu, Y.-P. Zhao, G. Ramanath, S.P. Murarka, G.-C. Wang, Thin Solid Films 384 (2001) 151-156.

[14] Y.-K. Sun, W.H. Weinberg, Journal of Chemical Physics 94 (1991) 4587-4599.

[15] M. R. Columbia, P. A. Thiel, Journal of Electroanalytical Chemistry 369 (1994) 1-14.

[16] S. Kim, D.J. Duquette, Journal of The Electrochemical Society 153 (2006) C673-C676.

[17] L. Wu, E. Eisenbraun, Journal of The Electrochemical Society 156 (2009) H734-H739.

[18] ～H. Kim, S.M. Rossnagel, Thin Solid Films 441 (2003) 311-316.

[19] H. Kim, T. Koseki, T. Ohba, T. Ohta, Y. Kojima, H. Sato, Y. Shimogaki, Journal of The Electrochemical Society 152 (2005) G594-G600.

[20] S.-H. Kwon, O.-K. Kwon, J.-S. Min, S.-W. Kang, Journal of The Electrochemical Society 153 (2006) G578-G581.

[21] S.-W. Kim, S.-H. Kwon, S.-J. Jeong, S.-W. Kang, Journal of The Electrochemical Society 155 (2008) H885-H888.

[22] S. Kumar, H.L. Xin, P. Ercius, D.A. Muller, E. Eisenbraun, IEEE 2008 International Interconnect Technology Conference (IITC 2008), Proceedings, pp. 96-98 (2008).

[23] S. Kumar, D. Greenslit, T. Chakraborty, E.T. Eisenbraun, Journal of Vacuum Science and Technology A 27 (2009) 572-576

[24] D. Greenslit, T. Chakraborty, E. Eisenbraun, Journal of Vacuum Science and Technology B 27 (2009) 631-636. 